\title{
The Impact of Cross - Culture on Employer's Brand Perception - Based on the Survey of Chinese and American Graduates' Data
}

\section{Huang Xing-Jun}

International Business School, Jinan University, Qianshan, Zhuhai, Guangdong, China.

*Corresponding Author: Email: 627103600@qq.com

\begin{abstract}
Cross-cultural factors are new elements that Chinese enterprises must consider when building their employer's brand in the era of economic globalization. This paper mainly discusses the difference between the perception of the employer's brand and the status of Chinese enterprises under the different culture background. The questionnaire survey was conducted on the graduates in China and the United States, by using the Employer Brand Attraction Scale developed by Berthon et al [1]. The relevant analysis was carried out using SPSS software to test and demonstrate the research hypothesis. This study draws the following conclusions: (1) There are differences between Chinese and American graduates 'expectation for employers; (2) Chinese and American graduates have different perceptions in Chinese enterprises' recognition; (3) In view of the survey results, suggestions of Employer Brand Development Strategy are given.
\end{abstract}

Keyword: Employer Brand; Cultural Differences; Status of Chinese Enterprises.

\section{Introduction}

As the competitive environment changes, talent capital has become the most important factor in the contemporary era. How to attract talents through effective methods has become the most important thing for today's enterprises. Building a good employer brand is indispensable. In addition, under the background of economic globalization, Chinese companies have started to develop more and more abroad.

How do Chinese companies establish a good employer brand image in a cross-cultural context has become a very important issue? The main purpose of this paper is to compare and analyze the perception of Employer brand importance and Chinese employer brand status among Chinese and American graduates, explore the cultural roots behind the differences in employer brand influence factors, Based on the different factors influencing the perception of employer brand importance between the Chinese and Western, this paper puts forward the feasible suggestions for the construction of Chinese enterprises' employer brand in transnational operations.

\section{Literature Review}

\section{Defining Employer Brand}

Employer branding is the result of the application of marketing principles to human resource management [2]. Employer branding is an extension of brand theory in the field of human resources [3]. Research that related to employer branding began in the United States in the earliest was Fortune magazine's "Best Employers" ranking event in 1984. Ambler and Barrow first conceptualized the term in their paper "Employer Brand" in 1996. They believe that the concept of branding can be applied to recruitment. It is an image 
feature of a job seeker identifying the employer and distinguishing it from other employers. It embodies a combination of functional, economic, and psychological benefits that are provided by employers and linked to employers. [4].

\section{Measurement Dimensions of Employer Brand}

Since the concept of employer brand was proposed, researchers are very concerned about how to attract outstanding potential applicants through employer branding. Jiang and Iles [5] regard it as a "magnetic field", attracting applicants' attention to employer brands, and encouraging employees become loyal to the company [5]. When Ambler and Barrow proposed the concept of employer brand in 1996, they explained there are three factors, functional, economic, and psychological benefits.

Functional benefits refer to opportunities provided by employers to employees for career development or other activities. Economic benefits refer to the compensation provided to employees. While the psychological benefits refer to the feelings and experiences of the employees in terms of their attribution, direction, and goals, etc.[4]. According to Stevens and Collins'study, employer brands can be divided in ten dimensions: fun work, good training programs, company reputation, corporate culture and job security, work environment, promotion opportunities, opportunities for learning new skills, wages, and benefits [6].

In the study of bank employees and related student groups, Lievens \& Highhouse firstly introduced the concept of symbolic features of marketing into the field of employer brand research. Job seekers also value symbolic aspects in the job search process. Symbolic factors mainly include five aspects of sincerity innovation, competence, prestige, and health. And they also found that different groups have different attention level to functional factors [7].
Berthon et al. developed and validated multi-project scales to identify and implement the components of employer attractiveness in 2005. The author considers five different dimensions of employer attraction (eg, development factors, social factors, interest factors, Economic factors and applied factors), and provide evidence of the validity and reliability of their scale [1].

Although there are large differences in the dimensions distinguished, almost all scales include compensation and benefits, growth and development, job content, organizational culture, and personal value. This study refers to the multi-project scale which developed and validated by Berthon et al in [1], it divides the measurement of employer brands into five different dimensions (development factors, social factors, interest factors, economic factors, and application factors).

\section{Berthon's Theory for Employer Brand}

This theory is based on the three-factor theory of Ambler and Barrow. Through the method of induction and deduction, it finds two other factors of employer attractiveness.

$\mathrm{He}$ first interviewed undergraduate graduates from Australian universities for potential employers' considerations, summed up 32 qualitative items, then compiled 32 items into a 32-item scale, and distributed 683 university graduates.

Then reliability test of the scale yielded a 25-item employers' attractiveness scale. Lastly, the confirmatory factor analysis concludes that the employer brand attraction dimension is divided into five factors: development, socialization, interest, economy and application.

- Development factor: It refers to the employer's ability to help employees achieve self-worth, increase employee confidence, and improve their work skills and experience. 
- Social factor: It means that employers can provide an interesting working environment and provide good cooperation and team atmosphere.

- Interest factor: It means that employers can provide an exciting working environment, innovative work practices, and use their staff's creativity to produce high-quality, innovative products and services.

- Economic factor: It means that employers can provide compensations and benefits that are higher than the industry average, guarantee the stability of work, and have better opportunities for self-improvement.

- Application factor: It means that the employer provides an employee with the opportunity to show their own skills to others and teach others and provide humanitarianism in a customer-oriented environment.

\section{Hypothesis}

\section{Differences in Perceived Importance of Employer Brand}

As managers and academic researchers, it is very important to deeply understand the dimensions of the employer brand. Companies also need to understand the importance of each dimension in the employer branding attractiveness is different. Berthon et al [1] proposed that the measurement of the attractiveness in employer brand needs further verification in different cultures, for studying the differences in the attractiveness under different cultural backgrounds.

Ma \& Allen [8] proposed that cultural values may affect job seekers' attention to the attributes of the employer's image dimensions, and thus influence the further decision of the recruiter. [8] There are some empirical studies that have begun to test some of Berthon et al's recommendations and $\mathrm{Ma} \&$ Allen's claims. Baum \& Kabst[9] studied the relationship between employers' image characteristics and job seekers' intentions in different countries. [9] They investigated undergraduate engineering students in Europe (Germany and Hungary) and the Asia Pacific region (China and India). In these countries, the specific nature of work, such as the comfort of working life, the attractiveness of tasks, and the attractiveness of payment, have a different effect on different country job seekers.

Alniacik et al [10] explored Latvia's and Turkey's job seekers' different attitudes toward employers' brand attraction factors. Latvia valued factors such as "humanism, giving back to society, and demonstrating self-learning”. Christians et al [11] conducted research on recent students in Ukraine, the United Kingdom, and Latvia; he found that different cultural backgrounds do affect the choice of factors that students consider for their employers. Such as the "stability of work" dimension, Ukrainian students value the choice of employers the most, followed by Turkey, and finally in the United Kingdom.

The reason that this result is due to differences in the risk avoidance of uncertainty in the cultural dimensions. Hofstede et al [12] also pointed out that Ukraine has a higher degree of uncertainty and avoidance index than the United Kingdom; in this culture background employees will regard work as necessary for life. Worries about the risks of replacement work, so they will pay more attention to the stability of the work [12].

In addition, Christiaans et al. [11] also verified that students in the three countries are valued for factors such as starting salaries, working partnerships, and freedom-restrictions, and these factors can be explained through corresponding cultural dimensions. [11] Based on the above review, we get

\section{Hypothesis 1}

Hypothesis 1: There are significant differences in the perception of the importance of the employer brand dimension 
for job seekers of recent graduates under different cultural backgrounds.

Hypothesis 1a: Under the different cultural background between China and the United States, there is a significant difference in the perception of the importance of development factors in the employer brand dimension among job seekers of recent graduates

Hypothesis 1b: Under the different cultural background between China and the United States, there is a significant difference in the perception of the importance of social factors in the employer brand dimension among job seekers of recent graduates

Hypothesis 1c: Under the different cultural background between China and the United States, there is a significant difference in the perception of the importance of interest factors in the employer brand dimension among job seekers of recent graduates.

Hypothesis 1d: Under the different cultural background between China and the United States, there is a significant difference in the perception of the importance of economic factors in the employer brand dimension among job seekers of recent graduates

Hypothesis 1e: Under the different cultural background between China and the United States, there is a significant difference in the perception of the importance of application factors in the employer brand dimension among job seekers of recent graduates

\section{Differences in Perceived Status of Chinese Companies}

Froese et al [13] used the literature about the image of origin country (the beliefs of a country and the country's products) to study the reasons why Vietnamese students were attracted by Japanese and US companies in Vietnam. Because they have a good image of origin country, the key determinant is that Vietnamese students believe that these two countries are technologically advanced, so these companies have attracted a large number of job seekers. [13] However, Vietnamese students' evaluation of Japanese companies is significantly higher than that of American companies. The perception of Chinese employers' brand image has not been adequately studied. Moreover, under different cultural backgrounds, Chinese students' perceptions of Chinese employers' brand image should be different from those of American students. Therefore, we get

\section{Hypothesis 2}

Hypothesis 2: There is a significant difference in the perception of employers' brand status in Chinese enterprises under the different cultural backgrounds between China and the United States.

Hypothesis 2a: Under the different cultural background between China and the United States, there is a significant difference in the perception of the current status of the development factors in the dimension of the employer brand of Chinese enterprises.

Hypothesis 2b: Under the different cultural background between China and the United States, there is a significant difference in the perception of the current status of the social factors in the dimension of the employer brand of Chinese enterprises.

Hypothesis 2c: Under the different cultural background between China and the United States, there is a significant difference in the perception of the current status of the interest factors in the dimension of the employer brand of Chinese enterprises.

Hypothesis 2d: Under the different cultural background between China and the United States, there is a significant difference in the perception of the current status of the economic factors in the dimension of the employer brand of Chinese enterprises.

Hypothesis 2e: Under the different cultural background between China and the United 
States, there is a significant difference in the perception of the current status of the application factors in the dimension of the employer brand of Chinese enterprises.

\section{Methodology}

\section{Survey Design}

The questionnaire mainly uses the five-point Likert scale method and draws on the employer attractiveness scale developed by Berthon et al. [1] the scale has been adopted and validated by the research of many scholars. It can measure the importance of the employer brand dimension in multiple cultural contexts.

The questionnaire is divided into three parts, a total of 52 questions, the first part of the 25 questions is the measurement of the importance perception of the employer brand dimension, the second part 25 questions are the measurement of the perception about the dimensions of Chinese enterprise employer brand status, and the third part 2 questions are demographic characteristics and willingness to enter Chinese companies. The Chinese-English item translation of the questionnaire was back-translated. The ideas of the English and Chinese items were exactly the same, and they could be used for investigations in China-US language contexts.

\section{Data Collection}

The survey participants were divided into two parts. One part are American, Some of them were graduates from the business school of Drexel University in Philadelphia, and the undergraduates of the University of Pennsylvania.

The other part is Chinese, Some of them were graduates from financial engineering in Jinan University, and others are from the health management of the Southern Medical University. Sample data on U.S. graduates were obtained through paper questionnaires, while sample data on Chinese graduates were collected through online questionnaires.

\section{Method}

This study first refers to the results of factor analysis [1], and induces the first 25 items of the questionnaire into five factors: development, socialization, interest, economy, and application. Items $1,3,4,5$, and 6 were summarized as development factors, items 2 , $7,8,9$, and 23 were summarized as social factors, and items 10,11, 12, 13, and 14 were summarized as interests. Factors 15th, 21st, 22nd, 24th, and 25th are summarized as economic factors, and items 16, 17, 18, 19, and 20 are summarized as application factors [1].

Secondly, we calculates the average value of each item of the scale, and then sums the average of the items involved in each factor to calculate the average of each factor. For example, the mean of items $1,3,4,5$, and 6 is the importance perception score of development factors. In the end, this paper will compare the importance perception score of five different factors, and then, under the different cultural backgrounds of China and the United States, we compare the differences in importance perceptions of the employer's brand dimension among job seekers of different graduates, and the differences in perceived employer brand status of Chinese multinational enterprises.

\section{Results}

\section{Sample}

In the sample data of US graduates, 79 questionnaires were collected, including 70 valid questionnaires and ratio is $88.6 \%$. The 9 invalid questionnaires were all missing information and the questionnaires were answered incompletely. Among the 70 questionnaires, 47 questionnaires were answered by males, accounting for $66.7 \%$.

They indicated that they were willing to work in Chinese companies in 27 cases, with a ratio of $38.6 \%$. A total of 83 completed questionnaires were collected from the sample data of Chinese graduates. In order to 
better compare the data on both sides, 13 questionnaires with the shortest answer time were excluded because the shorter the answer time, the more likely it was to fill casually in the questionnaire. Therefore, there are also 70 sample data of Chinese graduates. Among the 70 questionnaires, 33 questionnaires were answered by males, accounting for $47.1 \%$, and 61 were willing to go to work in Chinese companies, with a ratio of $87.1 \%$.

\section{Hypothetical Test}

Table 1 shows the mean differences between Chinese and American graduates' perceptions of the overall importance and different dimensions importance of the employer brand. From the results, the Sig values of the three term of overall perception, development factors, and interest factors are less than 0.05 . hypothesis 1c are verified, and the Sig values of the three terms of social factors, economic factors and application factors are higher than 0.05. Therefore, hypotheses 1b, hypothesis $1 \mathrm{~d}$ and hypotheses $1 \mathrm{e}$ are not verified.

Table 2 shows the mean differences between Chinese and American graduates' perceptions in the status of Chinese employers' brands and their perceptions in different dimensions. From the results, the Sig values of the five terms of overall perceptions, development factors, social factors, interest factors, and economic factors are less than 0.05. So Hypothesis 2, Hypothesis 2a, Hypothesis 2b, Hypothesis 2c, Hypothesis 2d is verified. Only the Sig value of the term of application factors is greater than 0.05 , so hypothesis $2 \mathrm{e}$ are not verified.

So, Hypothesis 1, hypothesis 1a and

Table 1: Test of Mean Differences in the Perceived Importance of Employer Brand Factors among Chinese and U.S. Graduates

\begin{tabular}{|c|c|c|c|c|c|}
\hline & American & Chinese & D-value & F-value & 7.517 \\
\hline Overall perception & 3.81 & 4.12 & 0.31 & 3.954 \\
\hline Development factor & 3.81 & 4.25 & 0.44 & .009 \\
\hline Social factor & 3.78 & 4.19 & 0.41 & .008 \\
\hline Interest factor & 3.84 & 4.07 & 0.23 & .929 \\
\hline Economic factor & 3.90 & 4.07 & .0 .17 & .743 \\
\hline Application factor & 3.72 & 4.03 & 0.31 & .389 \\
\hline
\end{tabular}

Table 2: Test of Mean Differences in the Perceived status of Chinese Company Employer Brand among Chinese and U.S. Graduates

\begin{tabular}{|c|c|c|c|c|c|}
\hline & American & Chinese & D-value & F-value & Sig \\
\hline Overall perception & 2.99 & 3.38 & 0.39 & 46.835 & .000 \\
\hline Development factor & 2.98 & 3.43 & 0.45 & 23.390 & .000 \\
\hline Social factor & 3.02 & 3.47 & 0.45 & 8.337 & .004 \\
\hline Interest factor & 3.02 & 3.28 & 0.26 & 5.997 & .015 \\
\hline Economic factor & 2.93 & 3.32 & 0.39 & 5.893 & .015 \\
\hline Application factor & 2.98 & 3.39 & 0.41 & 3.260 & .071 \\
\hline
\end{tabular}

Difference

\section{between}

\section{Perceived}

Importance of Employer Brand and Perceived Status of Chinese Enterprise Employer Brand

Table3 is a comparison about the perception of the importance in employer branding and the perception of the status in Chinese employers' brands from American graduates. The expectations score of American graduates for different dimensions of employer brands are not too high and have not yet reached 4 points, but they are against Chinese employer brands, and perception of the status of Chinese employers' brands is below 3 points. 
It can be said that the Chinese enterprises are not recognized. Table 4 shows the comparison about the perception of the importance in employer branding and the perception of the status in Chinese employers' brands from Chinese graduates. The expectations score of Chinese graduates for different dimensions of employer brands are more than 4 points. It is considered that each dimension is more important, or Very important, but the perception of the status of Chinese employers' brands is significantly lower than the perception of importance.

Table 3: Comparison between Perceived Importance And Perceived Status from American Graduates

\begin{tabular}{|c|c|c|c|}
\hline & Perceived Importance & Perceived status & D-value \\
\hline Development factor & 3.81 & 2.98 & 0.83 \\
\hline Social factor & 3.78 & 3.02 & 0.76 \\
\hline Interest factor & 3.84 & 3.02 & 0.82 \\
\hline Economic factor & 3.90 & 2.93 & 0.97 \\
\hline Application factor & 3.72 & 2.98 & 0.74 \\
\hline
\end{tabular}

Table 4: Comparison between Perceived Importance And Perceived Status from Chinese Graduates

\begin{tabular}{|c|c|c|c|}
\hline & Perceived Importance & Perceived status & D-value \\
\hline Development factor & 4.31 & 3.43 & 0.88 \\
\hline Social factor & 4.21 & 3.47 & 0.74 \\
\hline Interest factor & 4.07 & 3.28 & 0.79 \\
\hline Economic factor & 4.07 & 3.32 & 0.75 \\
\hline Application factor & 4.03 & 3.39 & 0.64 \\
\hline
\end{tabular}

\section{Discussion}

The Cultural Background of the Differences in Perceived Importance of Employer Brand

Judging from the comparison about the mean score of perceived importance in employer branding dimensions between Chinese and American graduates, Chinese graduates have higher expectations or requirements for their future employers in the job search process. They generally believe that the five listed above dimensions are all very important. They hope that the companies that they will serve in the future can meet the above five requirements at the same time.

In comparison with the recent graduates of the United States, it is generally believed that the importance of the above five dimensions is generally important, and their expectations and requirements for their future employers are also relatively low.
This point can be explained from the cultural level. It can be found that Chinese people tend to pay more attention to work and career than Americans. When people talk about success, they pay more attention to external business success. Americans pay more attention to family and life experience, people measure the life with more inner happiness.

This can also be reflected by Hofstede's cultural dimension. China has a higher long-term orientation index than the United States. Chinese are more concerned about the future, advocating thrift and perseverance, while the United States is a typical short-term oriented culture. They pay more attention to the current.

The enjoyment of life makes it impossible for them to go too far in pursuit of career success as the Chinese do. The demands on their own careers in the workplace are not so high. 
At the same time, comparing to the dimension of self-indulgence-constraint, it is also more illustrative of this phenomenon. American culture has a higher indulgence index, while Chinese culture is very low. This will prompt Americans to be less willing to restrict their own desires to achieve future success, while Chinese people tend to Restraining current desires, forming a high degree of restraint on their own thoughts and behaviors and pursuing the values of "self-denial and tranquility". We can see that when Chinese people choose their employers, they often have higher expectations and hope that employers can help them.

\section{The Causes of the Differences in Perceived Status of Chinese Enterprises}

The perceived status of Chinese employer brands by Chinese and American graduates is same as the perception of importance factors. American graduates score in five dimensions is lower than Chinese graduates. This may be caused by they set up different reference for Chinese companies. Chinese graduates are more likely to use domestic companies as the reference standard, while US graduates are more likely to use American companies as reference standards.

Therefore, U.S. graduates are worse than Chinese graduates in perception of Chinese employers' brand status. Another point worth considering is that Chinese companies are rooted in China, which may allow Chinese companies to use more energy to consolidate its roots, thus creating a better employer brand image.

\section{Suggestions on Chinese Enterprises' Employer Brand Construction}

Chinese employer should pay more efforts to increase strength so that it can increase salaries and benefits.

The economic factor is the most important

\section{References}

1. Pierre Berthon, Michael Ewing, Li Lian Hah (2005) Captivating company: Dimensions of factor considered by recent graduates in the United States. However, in their minds, Chinese companies are doing the worst in this respect. Therefore, when Chinese companies improve their image of employers in the eyes of US jobseekers, they must pay attention to the average industry treatment in the United States.

However, the increase in wages and benefits is based on stronger corporate strength and higher profitability. Meanwhile, Maintaining product status and $R \& D$ innovation spirit is Equally important. Domestic Subsidiaries should improve the promotion mechanism and break the age limit.

\section{Limitation}

The scope of the sample needs to be further expanded. Only 140 samples were used in this study. There were 70 samples from both China and the United States. The number of samples was relatively small. (2) The cultural background barriers of the questionnaire cannot be overcome. The questionnaire mainly uses the scale developed by Berthon et al. [1].

The scale was developed in the context of Western culture. When it uses to Chinese sample collection, there will be a certain amount of error. (3) This study doesn't specify certain industries in China to test the current status of employer brands, graduates in the United States may have different perceptions of employer image of Chinese companies in different industries. (4) This study is limited to sample surveys between China and the United States. The result may not be applicable to other country samples

attractiveness in employer branding $[J]$, International Journal of Advertising, 


\section{4(2):151-172}

2. Cable DM, Turban DB (2003) The value of organizational image in the recruitment context: a brand equity perspective [J], Journal of Applied Social Psychology, 33:2244-66

3. Backhaus K, Tikoo S (2004) Conceptualizing and Researching Employer Branding [J], Career Development International, 9(5):501-517

4. Ambler, T. and Barrow, S. The employer brand [J], Journal of Brand Management, 1996, 4 (3):185-206

5. Jiang TT, Iles P(2011) Employer-brand equity, organizational attractiveness and talent management in the Zhejiang private sector, China[J], Journal of Technology Management in China, 6(1):97-110.

6. Collins CJ, Stevens CK (2002) the relationship between early recruitment related activities and the application decisions of new labor-market entrants: A brand equity approach to recruitment [J]. Journal of Applied Psychology, 87:1121-1133.

7. Lievens F, Highhouse S (2003) the relation of instrumental and symbolic attributes to a company's attractiveness as an employer [J]. Personnel Psychology, 56:75-102.

8. Ma R, Allen DG (2009) Recruiting across cultures: a value-based model of recruitment. Hum. Res. Manag. Rev. 19:334-46.
9. Baum M, Kabst R (2013) How to attract applicants in the Atlantic versus the Asia-Pacific region? Across-national analysis on China, India, Germany, and Hungary. J. World Bus. 48:175-85

10. Esra Alnıaçıka, Ümit Alnıaçıka, Serhat Eratb, Kültigin Akçinb (2014) Attracting Talented Employees to the Company: Do We Need Different Employer Branding Strategies in Different Cultures? $[\mathrm{M}]$, 10th International Strategic Management Conference, Procedia-Social and Behavioral Sciences,150, 336-344.

11. Christiaans L (2012) International employer brand management: A multilevel analysis and segmentation of students' preferences [J]. Gabler p. 1-12.

12. Hofstede G, Hofstede GJ, Minkov M (2011) Kultury i organizacje: Zaprogramowanie umyslu (3rd ed) [J], P.1-20

13. Froese FJ, VO A, Garrett TC (2010) 'Organizational attractiveness of foreign based companies: a country of origin perspective', International Journal of Selection and Assessment, 18:271-281. 